\title{
2. The main objectives of the project
}

The overall objective of the project has been to re-design the research agenda for MABAustria, in special consideration of BRIM. Furthermore, the project specified a few other objectives in support, and in addition, to the main objective. We summarize below the main goals of the project.

7 Investigations for a possible research agenda for MAB Austria, in special consideration of BRIM.

8 Engender communication with the scientific community with respect to MAB research in Austria.

9 Guidance for the allocation of resources to MAB research in Austria

10 Signal to funding agencies the importance of this research

11 Integrate Austrian MAB activities to UNESCO-MAB and other national MAB activities

12 Link the Austrian MAB programme to other international programmes

\section{Activities undertaken in relation to their objectives}

\section{Objective 1. Investigations for a possible research agenda for MAB Austria, in special consideration of BRIM}

Activity 1: Research on the status of BRIM (national and international) via interviews, questionnaires, and literature surveys.

As was emphasised in the proposal, the new Austrian MAB research agenda was to be redesigned in special consideration of the Biosphere Reserve Integrated Monitoring (BRIM) concept as laid down in the Sevilla Strategy in 1995 and reinforced 5 years later. The concept of "integrated monitoring" for BRs was expressed as an interdisciplinary effort (between the natural and social sciences) for the development and use of concepts, 